\title{
Research on Ideological and Political Theory Courses in Teaching Chinese to Speakers of Other Languages
}

\author{
Feng Doudou ${ }^{1, \mathrm{a}}$
}

\author{
${ }^{1}$ Shaanxi University of Chinese Medicine \\ aEmail:3237875309@qq.com
}

\begin{abstract}
Talents majoring in Teachers of Chinese to Speakers of Other Languages (TCSOL) bear the responsibility of spreading Chinese culture and telling Chinese stories. However, there are many problems in the process of spreading Chinese culture, such as political position, cultural confidence and cultural ideology. Based on the above problems and the proposal of the ideological and political ideas of the curriculum, this paper carried out a study on the ideological and political ideas of the cultural curriculum of the major of TCSOL, as well as the problems in the course of cultivating talents of this specialty and the measures of ideological and political implementation of cultural courses. The ideological and political courses will be closely combined with professional courses in order to cultivate outstanding international professionals with high-level application, so as to better promote the dissemination of Chinese culture and let more people know about China.
\end{abstract}

Keywords: Ideological and political courses, TCSOL, education mode, educational strategy

\section{汉语国际教育专业文化课程思政的研究}

\author{
冯豆豆 1 , a
}

\author{
1 陕西中医药大学南校区 \\ a邮箱: 3237875309@qq.com
}

\begin{abstract}
摘要
汉语国际教育专业的人才承担着中华文化的传播，中国故事的讲述职责，但在中华文化传播过程中出现了许多 的问题例如政治站位、文化自信和文化意识形态等。基于以上出现的问题及课程思政理念的提出此论文围绕汉 语国际教育专业文化课程思政展开研究，研究内容分析了该专业文化课程思政的必要性; 该专业人才培养过程 中出现的问题及文化课程思政实施的举措。将课程思政与专业课程紧密结合以便培养优秀的集高层次应用性 复合型国际化专门人才，从而使其更好地促进中华文化传播，让更多人了解中国。
\end{abstract}

关键词: 文化课程、课程思政、汉语国际教育专业、举措

\section{1.引言}

通过在中国知网搜索汉语国际教育专业与课程 思政这一主题, 结果发现 7 条相关文献, 而搜索课程 思政这一主题结果发现 15971 条相关文献, 搜索中华 文化课程思政结果显示 96 条相关文献。通过以上数 据可看出随着课程思政这一理念的提出有关此内容 的研究较多, 但有关汉语国际教育课程思政的相关研 究较少, 而与此专业文化课程相关研究几乎没有。因 此关于汉语国际教育文化课程思政的研究具有很大
的潜力。“课程思政”这一理念是社会发展的产物, 是 将思想政治教育与专业基本课程相结合的一种教学 改革, 与专业基础课程的整个学习过程形成一种同向 同行, 共同发展的教学方式。此专业人才承担着中华 优秀传统文化的传播重任, 他们的价值观念、文化自 信、意识形态等在其中具有极大的支配作用，因此汉 语国际教育专业教师课程不仅需要传授知识技能还 需要在专业课程中渗透思政教育让他们潜移默化的 树立正确思想价值观念，从而做一名合格的中华文化 传播者。 


\section{2.汉语国际教育专业人才培养中存在的问题}

中国综合国力的提升使得越来越多的人想要学 习汉语了解中华文化, 相对应汉语国际教育人才量的 需求增大，但在汉语国际教育人才培养中出现了许多 问题我通过查阅文献和实地调查发现主要有以下几 个方面的问题。

\section{1 汉语国际教育专业文化课程教材没有统一 的标准}

虽然汉语国际教育专业近些年来得到了长足的 发展, 开设此专业的院校也日益增多, 但是由于缺乏 统一的文化课程教材, 各个院校对于文化教学在重难 点、优劣势方面的内容选择上五花八门, 导致汉语国 际教育人才培养在文化传播过程中各不相同, 不利于 中华优秀传统文化的传承与发展。加之“课程思政”理 念的提出, 将其与汉语国际教育的融合对于教学更加 增大了难度, 由于该专业人才培养的文化课程缺乏统 一性。

\section{2 汉语国际教育人才流失严重}

汉语国际教育专业的人才培养目标主要是掌握 汉语基础知识和汉语技能, 传播中华优秀传统文化, 将来主要从事国际汉语教学工作的人才, 但由于学习 者的思想价值观的存在如报效家园, 居家意识等阻碍 了职业发展方向。由于对于全球化意识和职业发展方 向的欠缺, 汉语国际教育专业人才主要从事国内的语 文教学, 而这与教育学相关专业并无二致, 未能很好 的发挥此专业的优势。同时此专业培养人才主要是在 国内的自己母语环境中进行基础知识学习缺乏在他 国实际的教学环境, 导致此专业人才跨文化交际能力 薄弱, 导致此专业人才害怕出国使得此专业人才未发 挥其真正的价值。

\section{3 汉语国际教育课程思政教育课程的缺失}

通过文献检索和实地调查发现大部分开设汉语 国际教育专业的院校所开设的文化课程在教学过程 中教师只是进行基本知识的讲授，而思政教育被忽略。 另外通过了解各高校汉语国际教育课程内容可发现 思政课程很少涉及或者只是在入学后进行专业的课 程进行集中学习后, 在后面的学习中不在安排。教学 的根本目标是立德树人, 学习目的是先学会做人再学 会做事。而汉语国际教育专业承担着传播中华优秀传 统文化的重任, 树立正确的思想价值观念、职业理念 等对于其在今后的职业生涯中具有重要意义。自 2016 年课程思政这一理念提出, 思政教育在教学中被提至 重要地位, 汉语国际教育文化课程思政的缺乏与这一 理念是不符的, 因此各高校应加强在专业课程教学中 融入思政教育。

\section{3.汉语国际教育专业文化课程思政的必要性}

\section{1 增强文化自信和文化认同感的需要}

中国传统文化给予文化自信深厚历史底蕴, 文化 是一个国家、一个民族的灵魂。文化兴国运兴, 文化 强民族强, 文化自信凝聚民族精气神, 是一个国家综 合实力的集中体现。汉语国际教育专业培养的人才主 要从事国际汉语教学传授中华优秀传统文化, 但在中 华优秀传统文化传播过程中, 少部分汉语国际教育专 业大学生理想信念缺失, 人生观、世界观、价值观偏 离, 个人主义、拜金主义和享乐主义仍不同程度存在。 为改变此现象各高校应在汉语国际教育教学中增强 学习者的文化认同感和文化自信从而更好传播中华 优秀传统文化进而增强中华文化国际影响力。

\section{2 人才培养方案的要求}

汉语国际教育专业人才培养目标是培养掌握扎 实的汉语言基础知识和技能, 有较高的人文素养, 具 备中国文化、跨文化交际及对外汉语教学等方面的专 业知识与能力, 能在国内外各类学校从事对外汉语教 学、推广中华文化的能力,具备一-定的涉外知识和外 语交际能力, 能在教育、外事、商贸、文艺、党政等 领域从事教学、研究、翻译、管理等工作, 具有创新 精神和实践能力的复合型人才。汉语国际教育专业人 才在传播中华优秀传统文化方面发挥着重要地位, 因 此在该专业文化课程教学中应该重视思政教育, 因为 该专业人才从事的职业面对这国际社会, 虽然如今的 社会总体处于一种和平与发展的时代, 但国际形势仍 然纷繁复杂, 整个社会发展是一种全球化多元化趋势 状态, 在这样的时代发展潮流中国际汉语培养人才代 表着中国的形象，必须因此培养其文化自信、文化自 觉意识、明确的政治站位、坚定的理想信念、崇高的 职业精神和强烈的社会责任感, 只有这样才能够成为 一名合格的中华文化传播者。

\section{3 新的教育教学理念的需要}

传统的教学理念是各课程各司其职, 各谋其业, 专业课程的教学与思政教育教学是孤立式的教学方 式, 这使得学生学习枯燥无味, 学习产生疲倦感。通 过文献阅读和调查发现各高校此专业课程与思政课 程的设置一般是分离的且思政课程涉及的主要内容 为习近平新时代中国特色社会主义理论体系、自然辩 证法等理论性极强的课程。2016 年, 习近平总书记在 全国高校思想政治工作会议上强调, 要用好课堂教学 这个主渠道, 各类课程都要与思想政治理论课同向同 行形成协同效应。这导致了两种不好现象的产生: 学 习者对于学习内容产生了疲倦心里从而影响学习效 率; 专业课程与思政教育分离使得思政课程教学出现 “孤岛化”的现象, 不利于思政教育教学进展和落实。 如今的教育教学理念强调“全人”教育即强调教育应 该是一种综合性的教育教学理念, 注重素质教育在教 
学实施中把知识转化为能力和良好素质, 将知识、能 力和素质三者结合体现整体性和谐发展。因此应加强 专业课程与思政课程结合适应新的教育教学理念。

\section{4 汉语国际教育专业学科特点、性质的决定 性}

汉语国际教育专业是为培养优秀的中华文化传 播者、博大精深的汉语知识传授者而设置, 这体现了 该专业本身就有一种课程思政教育。各高校该学科设 置课程大致都有跨文化交际、中华文化等，这些课程 内容讲述的过程会潜移默化增加他们对中华文化的 自信, 这一角度同样看出该学科与思政教育的相通性。 学科特点: 汉语国际教育是一门综合、边缘学科, 在 此专业的教学研究过程中依据的理论基础涉及语言 学、心里学、教育学、文化学。而课程思政教育理念 同样也强调综合性教育教学，二者具有相通性。

\section{4.汉语国际教育文化课程思政的实施措施}

\section{1 更新汉语国际教育专业的教学观念}

汉语国际教育的传统教育教学理念是专业课程 教学与思政教育课程分离, 专业课程教学主要进行知 识的讲解和传授, 思政课程专攻思政教育促使学生形 成积极向上的心里, 拥有正确的价值观、人生观和世 界观。如今人教育教学强调“全人”教育, 目标是促使 学生形成德智体美劳全面发展。因此该专业文化课程 也应顺应时代发展更新自己的教学理念将思政教育 贯穿于教学大纲、课程设计和实践活动等整个教学过 程以便更好的引导学生树立正确价值观。在具体文化 的课程设计中有效将现今社会主义核心价值观、习近 平新时代中国特色社会主义思想融入其中, 从而使学 生在学习文化知识同时受到思政教育。

\section{2 挖掘中华文化课程的思政内容}

中华文化渊源流长、博大精深, 优秀的中华传统 文化本身蕴含着大量的思政教育因素, 如体现爱国教 育的文化知识, 张载的“为天地立心, 为生民立命, 为 往圣继绝学, 为万世开太平”言语虽短却包括了宇宙 观、道德观、价值观等思想观念, 形象地将中华民族 自强不息、厚德载物品质展现; 儒家学派提倡的“修身, 齐家, 治国, 平天下”; “仁义礼智信”; 中国在古代的 卖身葬父、亲尝汤药等孝道故事; 中国古代的成语故 事及寓言故事例如“女娲补天”、“夸父逐日”等成语流 传至今形象地展现了人们的思维方式和观念; 还有中 国古代卓越的建筑模式及装饰很好的展现了古人聪 明的智慧。而这些内容无不体现了思政教育因素，同 时可以很好地增强人们的自信心和自豪感。优秀中华 传统文化本身就是一种思政教育, 如程裕祯的中华文 化要略教材中内容就包含了大量思政教育因素, 这些 知识的学习有利于增强学生对中华文化的自信和认 同感。

\section{3 构建“上下一体”的文化课程思政教学体系 和新的教学模式}

\subsection{1 教学体系}

首先国家和教育部应出台相关政策以支持专业 课程与思政教育的结合发展; 其次各高校应重视思政 教育与专业课程结合的发展, 制定相关规范、开展课 程思政教育理念的相关讲座，让师生意识到该理念发 展进步性和必要性; 各专业人才培养方案应将思政教 育纳入其中使得思政教育贯穿于整个教学过程, 各高 校带课老师应自觉将此理念融入课程设计使得学生 获得双重收获, 形成国家和高校上下一体的文化课程 思政教学体系。

\subsection{2 教学模式}

传统的教学模式主要通过知识传授的传统课堂 教学为主, 这与新的教育教学理念不相符不利于教育 教学的展开和进步。我们应该紧随时代发展潮流, 充 分利用科学技术服务于汉语国际教育文化课程思政 教育如课堂教学中利用多媒体技术进行中华优秀传 统文化的传统建筑展示让学生直观立体的感受传统 文化辉煌成就，从而增强文化自信; 结合微信等社交 媒体进行文化思政教育; 利用直播课、智能网络教育 平台等信息化教学手段进行文化课程思政教育。除了 以上的文化课程思政教育教学方式, 还可以增加与文 化课程思政教育课堂相匹配的社会实践活动如参加 历史博物馆等让学生亲身体验中华优秀传统文化。

\section{4 重建汉语国际教育文化课程考核评价体系}

传统的专业课程教学的考核评价方式构成主要 由中期测试、期末测试和平时成绩三大部分组成，从 此可看出传统的专业课程教学的考核评价注重知识 掌握测试, 虽然平时成绩中涉及到了实践活动的能力 测试, 但极少且不易测出学生真正的实践能力和从专 业课程学习中获得的思政教育的内容。因此汉语国际 教育文化课程的考核评价应将专业文化课程知识测 试与思政知识测试相统一, 促使学生形成德智体美劳 全面发展。具体举措如增加实践活动考核从他们的行 动中感受他们通过专业课程教学之外收获的思政教 育, 让他们不仅学习到知识更要学习到做人做事道理。

\section{5.结论}

汉语国际教育专业人才作为中华优秀传统文化 的传播者和代言人，面对复杂的国际形势应始终坚定 自己的政治立场，树立正确的思想价值观念、拥有坚 定的理想信念、高度的文化自信。“课程思政”这一教 学理念的提出对于汉语国际教育专业的人才培养具 有极大的意义, 该专业应重视将此理念贯穿于整个教 学过程从而服务于汉语国际教育专业人才的培养, 以 便培养出合格的中华优秀传统文化传播者。 


\section{REFERENCES}

[1] Siwei Yang. Analysis on the Teaching Mode of "Curriculum Ideology" for Chinese International Communication Talents in Colleges and Universities [J]. Journal of Southwest Forestry University (Social Sciences),2020,4(06):89-91+106.

[2] Yanfang Zhou. Analysis on the Ideological and Political Practices of Teaching Chinese as a Foreign Language [J]. Journal of Educational Theory and Practice,2020,40(33):36-38.

[3] Haiyan Lin. The Ideological and Political Research of "Introduction to Chinese International Education" Course under the Concept of Golden Curriculum Construction $[\mathrm{J}]$. Journal of Changchun University,2020,30(10):81-84.

[4] Xue Mao. Exploration and Practice of "Curriculum Ideology" in Chinese Classroom for International Students from the Perspective of "One Belt and One Road" -- Taking Chinese International Education as an Example [J]. Henan Education (Higher Education), 2020, (09):34-37.

[5] Yu Zheng. A Study on the Ideological and Political Construction of the Course of Teaching Chinese as a Foreign Language -- On the Characteristics of the Course Reform of Shanghai International Studies University $[\mathrm{J}]$. Chinese Language Education International (Chinese \& English),2020,5(03):12-19.

[6] Fan Sun. Practical Principles of the Ideological and Political Course of Chinese International Education -- Based on the Perspective of the Community of Human Destiny [J]. Journal of Educational Theory and Practice,2020,40(18):41-43.

[7] Xueying Sun. Reform and Exploration of Ancient Chinese Curriculum under the Concept of Curriculum Ideology and Politics -- Taking Teaching Chinese as an International Major as an Example [J]. Journal of Lanzhou University of Arts and Sciences (Social Science Edition), 2019, 35(06):94-99.

[8] Lin Wang. Study on Cultural Curriculum Setting for Master's Degree in Teaching Chinese as a Foreign Language [D]. Liaoning Normal University,2020.

[9] Xueqing Kong. Problems in the Training of Talents in Teaching Chinese to Speakers of Other Languages and Solutions [J]. Journal of Hubei Open Vocational College,2020,33(23):116-117+120.

[10] Xi Jinping's Thought on Socialism with Chinese Characteristics for a New Era $[\mathrm{M}]$. Beijing: Learning Press, 2018. 